\title{
OBISPOS PROCEDENTES DE CASTILLA Y PROYECTOS DE REFORMA EN LA SEDE DE COIMBRA (1358-1407)
}

POR

\author{
Rafael SÁnchez Sesa
}

Universidad Complutense de Madrid

\section{RESUMEN}

El estudio se centra en el obispado de Coimbra en un período en el que se suceden seis prelados de origen castellano, implicados de una u otra forma en proyectos reformadores. La permeabilidad de las fronteras políticas en el ámbito eclesiástico explicaría en buena medida la presencia continuada de prelados castellanos en una sede portuguesa, prelados que influyeron en los posteriores intentos de reforma en la iglesia lusitana.

\section{Abstract}

This study is about the bishopric of Coimbra in a period where are six prelates of Castilian origin. They are implied in reforming projects. The permeability of the political frontiers in the ecclesiastic area would explain the continued presence of Castilian prelates in a Portuguese see. These prelates influenced in the next tries to reform the Portugal Church.

Con la presente comunicación pretendemos ofrecer alguna luz sobre dos aspectos de la historia eclesiástica del Medievo: la relación frontera-iglesia y los proyectos de reforma. Nuestro análisis se centrará en unas determinadas coordenadas espacio-temporales -la sede conimbricense en la segunda mitad del siglo XIV y primeros años del XV-, dejando los marcos explicativos globales para mejor ocasión. 


\section{La Iglesia en PORTUGal EN LA SEgUNDA MTtAD DEL SIGLO XIV Y PRIMEROS AÑOS DEL XV.}

Como en el resto de Europa, el Cisma de Occidente funciona desde 1378 como hilo conductor de las vicisitudes de la iglesia portuguesa.

En el fondo de los frecuentes cambios de obediencia se encuentra la rivalidad anglo-francesa, ya que a cada nueva posición corresponde una nueva estrategia en el juego de las alianzas. A un período de neutralidad o incertidumbre (1378-1379) le seguirá el reconocimiento oficial de Clemente VII, confirmado por dos cartas del Duque de Anjou'. Como contraprestación por dicha obediencia Avignon concederá diversas gracias a la Universidad de Lisboa (In superne dignitatis apostolice), a las diócesis limítrofes con Castilla (Nuper per parte carissimi) y a los naturales del reino de Portugal ${ }^{2}$. La guerra con Castilla y la renovación de la alianza con Inglaterra suponen un cambio de obediencia religiosa y el reconocimiento de Urbano $\mathrm{VI}^{3}$. Tras la firma de la paz con Castilla, el rey Fernando I no llegó a reconocer oficialmente de nuevo a Clemente VII, según confirma una bula de Bonifacio IX habilitando al Maestre de Avis como rey de Portugal ${ }^{4}$. Durante la guerra entre el Maestre y Juan I de Castilla la obediencia a Urbano VI se convierte en un arma política al conllevar la condición de cismáticos de los reyes de Castilla y así poder evitar el sometimiento a los dictados de Juan I, legalmente rey de Portugal ${ }^{5}$. Por ello, cuando Joao das Regras en las cortes de Coimbra - a la que asisten sólo los obispos urbanistas-legitime la candidatura de Joao I como rey de Portugal frente a las de los traidores Dinis y Joao, el cismático Juan I y la ilegítima Beatriz, lo hará en

I Julio Cesar BAPTISTA, «Portugal e o Cisma do Occidente», en Lusitania Sacra, I (1956), Apéndices III y IV, pp. 185-187. Se trata de dos misivas en las que eł Duque de Anjou da sa opinión acerca del Cisma y de la política a seguir al rey de Portugal y agradece al obispo de Lisboa los servicios prestados a la causa clementista, además de alumbrar su proyecto para el casamiento de Dofia Beatriz con uno de sus hijos (1379).

2 Ibid., Apéndices V-X, pp. 187-195. En 1380 Clemente VII, entre otras mercedes, dispenso a la infanta Beatriz para casarse con sus consanguíneos - los Trastámara castellanos-, encargó la remodelación de las diócesis portuguesas a los adictos obispo de Viseu y abad de Alcobaça, concedió el privilegio de libre enseñanza a los doctores de Lisboa, dispuso parte de los bienes de las diócesis de Braga y Lisboa a favor del maestre y de la universidad lisboeta y absolvió a Pedro Álvares Pereira de todos los impedimentos para ser prior de la Orden del Hospital - provisión que encarga al también adicto obispo de Evora.

${ }^{3}$ Ibid., Apéndice XI, pp. 195-196. Urbano VI concedió indulgencias a todo aquel que ayudara a las tropas del Duque de Lancaster contra Castilla, otorgándole el título y privilegio de cruzado (1383).

4 El 27 de enero de 1391 en Roma Bonifacio IX habilitó como monarca a Joao I, quien siendo «Mestre de Aviz o adulterino, possa casar e ser rey» (Arquivos Nacionais/Torre do Tombo (AN/TT), 0930, Núcleo Antigo (NA), $n^{\circ} 39$, Livro de Bulas e Breves., fols. 46r-48r).

5 Julio Cesar BAPTISTA, «Portugal e o Cisma do Occidente»..., p. 172: «Em parte alguma da cristandade a cisao religiosa serviu de instrumento político tao valioso como em Portugal».

$I^{\text {er }}$ Congreso de Historia de la Iglesia

Hispania Sacra 51 (1999) 
nombre de la defensa del reino de sus «inimigos, mormente cismáticos e reveses de Santa Egreja» y por «levar por diante a honra de Urbano VI $\gg^{6}$.

A pesar de la crisis general de la iglesia se inician los primeros movimientos reformadores en el seno de la misma, encabezados en Portugal por los Jerónimos, de los que hablaremos más adelante, y por los Loios o cónegos regulares de Sao Joao Evangelista (1425), fundación lisboeta de Mestre Joao Vicente, Martim Lourenço Arvelo y Alfonso Nogueira, obispo de Lisboa'.

Los siglos bajomedievales marcan casi definitivamente la organización y geografía eclesiástica del reino de Portugal y su segregación de las instancias castellanas. Con la bula In Eminentissimae Dignitatis (10/11/1393), Bonifacio IX designa sede metropolitana a Lisboa, de la que dependerán en el futuro los obispados de Evora, Lamego, Guarda y Silves. Las diócesis leonesas y gallegas dependientes de Braga se liberan ${ }^{8}$ y la separación eclesiástica de Castilla y Portugal, auspiciada por las diferencias en el orden político, se ve confirmada en las provincias canónicas de Riba-Coa - de Ciudad Rodrigo a Lamego, según documento de Bonifacio IX (1403) -, Minho-Lima - de Tuy a Ceuta - y Guadiana - de Badajoz a Ceuta, según bula de Eugenio IV (1444)9.

Los caballeros portugueses de las ordenes militares de Calatrava y Santiago también se independizan oficialmente de Castilla en 1440, gracias a otra bula de Eugenio IV ${ }^{10}$. En principio los maestres de las 6rdenes portuguesas ${ }^{11}-$ Cristo, Santiago y Avis - eran nombrados por el papa, pero desde el siglo XV los nombramientos terminaron por recaer siempre en el seno de la familia real. El ejemplo más ilustre de dicha política, continuada en España por Fernando el Católico, fue el Infante don Enrique, maestre de Cristo ${ }^{12}$.

Por lo que respecta al culto y a la vida religiosa nos encontramos en un período de cambios. La celebración del Corpus Christi se establece en Braga con el arzobispo Lourenço Vicente (1374-1397) ${ }^{13}$. Surgen o se consolidan nuevas devociones de marcado carácter nacional. Tal es el caso de la festividad de

\footnotetext{
6 Ibid., p. 178.

7 Artur Roque de ALMEIDA, Para ler a histbria da Igreja em Portugal, Porto, Perpétuo Socorro, 1996, p. 76.

8 Ibid., pp. $75-113$.

9 Miguel de Oliveira, Historia eclesiástica de Portugal. Mem Martins, Europa/América, 1994, pp. 142-143.

$10 \mathrm{Ibid}$, p. 110.

I) Su actuación fue determinante en la guerra contra Castilla. El 26 de junio de 1397 Joao I pide a los caballeros, peones y ballesteros de las tierras del Maestrazgo de la Orden de Cristo que permanezcan atentos a las incursiones castellanas, pese al vigente período de tregua $(A N / T T$, Colecçao Especial (CE), caixa $\left.32, n^{\circ} 44\right)$.

12 Jbid., pp. 164-165.

13 Jbid, , p. 121.
} 
Nuestra Senhora en acción de gracias por la victoria de Aljubarrota, acaecida la víspera de la Asunción (14/8/1385). Con motivo de la misma el Condestable Nuno Álvares Pereira realizó una romería a Ourém el 17 de agosto de 1385, que repetiría en 1393 a Santa Maria da Seiça. Joao I hizo votos a Nuestra Senhora de Oilveira (Guimaraes) en agosto de 1385 y promocionó la construcción de un nuevo templo en dicho lugar en 1387, que antecedió a la fundación del cenobio dominico de Santa Maria da Vitoria en 1388. En Lisboa se instituyó la celebración de tres procesiones la semana de la Asunción, dirigidas respectivamente hacia el altar del Salvador del Convento de la Trinidad, hacia el Convento de San Francisco y hacia el templo agustino de Santa María de Graça. En la misma línea se inicia el culto a Sao Jorge. Relacionado con la alianza portuguesa con el Duque de Lancaster, su nombre sustituye al tradicional grito de Santiago en el campo de batalla, ahora patrimonio de los castellanos. En 1387 el rey incorpora su imagen a la procesión del Corpus. Por último en 1388 se erige una ermita bajo su advocación en Aljubarrota, en el lugar donde estuvo el estandarte de Joao I.

El siglo XIV marca el inicio de los acuerdos entre la Iglesia y la consolidada monarquía portuguesa, en tiempos enzarzadas en la pugna por el poder. La Iglesia ofrecerá un primer gesto con el reconocimiento del Beneplácito Regio en la concesión de beneficios durante las cortes o concordato de Elvas de 1361, en tiempos de Pedro ${ }^{14}$. Joao I alcanzará otros tres acuerdos con el clero luso. El primero de 10 de enero 1402 finalizó con otra resolución similar entre el rey y el arzobispo Martinho Afonso sobre la jurisdicción de Braga, que fue traspasada al rey a cambio de 4.000 libras de moneda antigua. El segundo de 13 de febrero de 1405 se resolvió con una resolución entre el rey y el obispo Gil Alma sobre la jurisdicción de Oporto, por la que dicha jurisdicción pasaba a manos del monarca a cambio de 3.000 libras anuales de moneda antigua ${ }^{15}$.El tercero y último data de 30 de abril de 1427 en Santarém y en él se resuelven diversos asuntos, entre ellos el citado beneplácito regio ${ }^{16}$. En este momento también tiene lugar el origen del derecho de patronato, que tanto juego dará en la expansión extraeuropea: tras la conquista de Ceuta, el miércoles 21 de

14 Ibid., p. 91 . La colaboración entre Iglesia y Monarquía puede verse reflejada en las bulas $R o$ manus Pontifex (18/3/1364) y Nuper Ex Certis (27/9/1365) por las que Urbano V concede dispensa a Pedro I de Castilla para casarse con la hija del rey de Portugal, condición indispensable para sellar la alianza luso-castellana (Pedro de AZEVEDO, «A coleç̧ao do Visconde de Carreira», en Boletim da Segunda Classe, Academia das Ciéncias de Lisboa, VIII (1913-14), Coimbra, 1915, pp. 183-205; AN/TT, CE, caixa 27 ).

15 La resolución inicial no dejó contentas a ambas partes pues el 9 de octubre de $\$ 405$ en Viterbo. Inocencio VII designa al arzobispo de Lisboa para que arbitre en dicho pleito sobre la jurisdicción de la ciudad de Oporto (AN/TT, 0930, NA, $n^{0} 39$, Livro de Bulas e Breves, fols. 48r-49r).

16 Miguel de OLIVEIRA, Historia eclesióstica de Portugal..., pp. 127-128.

IT Congreso de Historia de la Igiesia

Hispania Sacra 51 (1999) 
agosto de 1415 , se purifica la mezquita aljama de la ciudad y en ella se celebra la eucaristía el domingo siguiente. La empresa ceutí marcó el inicio de una nueva cruzada, sancionada por Martín V con su bula Sane Charissimus $(4 / 4 / 1418)^{17}$

La vida del clero monacal se caracteriza por su progresiva relajación: abuso de la encomienda -entre 1400 y 1500 no quedó monasterio con rentas sin abad comendatario-, excesivo número de fundaciones y falta de escrúpulos a la hora de reclutar religiosos ${ }^{18}$. No hay que infravalorar a la hora de analizar el problema la influencia de las sucesivas guerras entre Portugal y Castilla, como atestigua la documentación de la época ${ }^{19}$. La relación entre monacato y monarquía es muy estrecha y así, el monasterio cisterciense de Alcobaça es agraciado por Joao I con varios objetos tomados a los castellanos en Aljubarrota en compensación por la ayuda prestada por su abad Joao de Ornelas ${ }^{20}$.

Sin embargo, no faltan movimientos reformadores entre el clero conventual. Observantes franciscanos llegados de Galicia fundan un convento en Viana do Castelo (1392), cabeza de la reforma de la orden mendicante en Portu$\mathrm{gal}^{21}$. Los dominicos son reformados por Fray Vicente de Lisboa, confesor y capellán de Joao I. Su proceso de renovación se inicia con la instalación de una comunidad observante en el palacio de Benfica (1399) y concluye en su primera fase con la creación de una provincia portuguesa hacia el año1416 $6^{22}$. Por lo que atañe a los carmelitas, cabe destacar la fundación en tres fases de Nuestra

17 La promulgación de la cruzada estaría en la línea de anteriores concesiones papales al respecto. El 27 de febrero de 1355 en Avignon Inocencio VI concedió al rey Afonso IV la mitad de las décimas de todas las iglesias y monasterios de sus reinos por cuatro años para reconquistar las plazas que los moros habían tomado en el Algarbe (AN/TT, 0930,NA, $n^{\circ} 39$, Livro de Bulas e Breves, fols. 40r-42r). El 2 de abril de 1376 también en Avignon Gregorio XI expedía su bula Accedit Nobis por la que concedía al rey Fernando I la mitad de las décimas de todas las iglesias de sa reino por dos años para sufragar la guerra contra los moros (Pedro de AZEVEDo, «A colecçao do Visconde de Carreiras...; AN/TT, 0930, NA, n' 39, Livro de Bulas e Breves, fols, 45-46). El 12 de octubre de 1377 en la misma localidad el papa otorgaba al rey la mitad de las décimas de las iglesias de sus reinos durante dos años para sufragar la guerra contra Granada y los Benimerines y la potestad para fundar iglesias, catedrales y colegiatas en los lugares que conquistase, templos sobre los que podrá ejercer patronato y cobro de las correspondientes décimas (lbid., fols. $42 r-44 r$ ).

18 Miguel de OliverRa, Historia eclesiástica de Portugal..., p. 156.

19 Los ejemplos son numerosos: el 23 de julio de 1374 en Pedemeira Fernando I cede la aldea de Pataias al Monasterio de Santa Maria de Alcobaça, fundación real que había perdido parte de sus rentas «assim pelas pestelencias que foram, como pelas guerras que houvemos» (AN/TT, $C E$, caixa $31, n^{\circ} 23$ ). El 23 de mayo de 1400 en Alcántara Jozo I excusa a los caseros, mayordomos y labradores de las quintas del Monasterio de Santa Maria de Alcobaça para que puedar acudir a su llamamiento a la guerra contra Castilla ( $A N / T T, C E$, caixa $32,{ }^{\circ} 41$ ).

20 Miguel de OliveIRA, Historia eclesiástica de Portugal.., pp. 157-158.

21 Ibid., p. 159.

22 Ibid., p. 160 
Senhora do Vencimiento do Monte do Carmo en Lisboa. Tras la primera iniciativa del condestable Nuno Álvares Pereira (1389), se instalan varios carmelitas venidos de Moura en 1397, aunque su fundación definitiva data del año $1423^{23}$. Los jerónimos fueron introducidos en Portugal por Fray Vasco Martins, natural de Leira. Éste fundó un eremitorio en Penha Longa, en la Sierra de Sintra, y otro en Mato, en el Alenquer. En 1389 dichos eremitorios fueron aprobados por el papa y reconvertidos en conventos gracias al apoyo de Joao $\mathbf{I}^{24}$.

Si la vida del clero regular dejaba mucho que desear, la del clero secular no le iba a la zaga. El nivel moral y cultural del mismo eran bastante pobres, como atestiguan las disposiciones sinodales del arzobispo de Braga Lourenço Vicente (1374) o del metropolitano de Lisboa Joao Esteves de Azambuja $(1403)^{25}$.

El incumplimiento de la residencia y de otras obligaciones deterioraba el oficio divino. Prueba de ello es la visita a Santa María de Marvila en Santarém que realizó en 1402 el citado Joao Esteves de Azambuja con la finalidad de que las misas se celebrasen correctamente, sin los murmullos, habladurías y comentarios habituales ${ }^{26}$.

En dicha visita se establecen también algunas disposiciones sobre la enseñanza de la doctrina cristiana ${ }^{27}$. En los capítulos 2, 3 y 4 se establece que durante un año el párroco ha de enseñar los domingos y fiestas el Pater Noster y el Ave Maria en latín y el Credo en portugués, cuyo texto reproduce el libro de visita y constituye el primer ejemplo en portugués. Los domingos de Cuaresma

\footnotetext{
23 lbid., p. 160.

24 Ibid., p. 161.

25 Isáá da Rosa PEREIRA, A vida do clero e o ensino da doutrina crista através dos sínodos medievais portugueses (séculos XIII-XV), Lisboa, 1978. Es separata de Lusitania Sacra, 10 (1978), pp. 103-141.

${ }^{26}$ Ibid., p. 126. Sobre las visitas pastorales cabe citar el estudio de Isaras da Rosa PEREIRA, As visitas parroquiais como fonte histórica, Lisboa, 1973. Es separata de Revista da Faculdade de Letras de Lisboa, II Serie, 15 (1973), pp. 11 y ss.

27 José SÁNCHEZ HERRERO, «La enseñanza de la doctrina cristiana en Portugal de 1205 a 1505 dentro del contexto de la Península Ibérica", en Actas das II Jornadas Luso-Espanholas de Historia Medieval, vol. III, Porto, 1989, pp. 1159-1167. El artículo recoge los siguientes epígrafes:

1. Actividad conciliar y sinodal portuguesa de 1215 a 1505 .

2. Legislación conciliar y sinodal sobre la enseñanza de la doctrina cristiana. Cronología y estadística.

3. Descripción de las piezas portuguesas hasta boy conocidas sobre la enseñanza de la doctrina cristiana.

4. Tipología documental.

5. Contenido de la doctrina cristiana y su evolución.

6. Medios para la enseñanza de la doctrina cristiana.

También cabe citar a F. Da Gama CAEIRO, «Ensino e pregaçao teológica no contexto medieval peninsular», en Ibid., vol. IV, Porto, 1990, pp. 1349-1357.

$I^{\text {er }}$ Congreso de Historia de la Iglesia

Hispania Sacra 51 (1999)
} 
y Adviento el curado deberá aleccionar sobre los diez mandamientos, las siete obras de misericordia, los sacramentos y los siete pecados capitales ${ }^{28}$.

Pese a todo, la crisis espiritual no se percibe en el campo artístico. En el Monasterio de Batalha, fundado en memoria de la batalla de Aljubarrota por Joao I, trabajan Alfonso Domingues (1388-1402) y Huguete (1402-1438), representante del gotico de York que remata la iglesia, la casa del capítulo, la capilla de Joao I e incia en 1437 las capelas imperfeitas, finalizadas en tiempos de Manuel I (1495-1521).

Dejamos en último lugar un aspecto que toca de lleno el tema principal de nuestra comunicación, como es el trasvase de clérigos y prelados entre Portugal y Castilla y viceversa a finales del siglo XIV ${ }^{29}$. Resulta a todas luces decisivo el protagonismo de la guerra luso-castellana entre 1383 y 1385. En el transcurso de la misma muere el obispo de Lisboa Martinho Anes, el prior de la Colegiata de Guimaraes y la abadesa de Évora ${ }^{30}$. También tienen lugar la colaboración del obispo de Guarda con Juán I y el exilio en Castilla del prior Álvaro Gonçalves. De igual forma, se intensifica la participación del clero en las asambleas políticas (1383-1385) y alcanzan gran protagonismo figuras como la del ya mencionado Lourenço Vicente o la de Joao das Regras, nuevo prior de la Colegiata de Guimaraes, según conocemos a través del relato de Fernao Lopes.

El trasvase hacia Castilla, distinto al que a nosotros aquí nos interesa pero igualmente definitorio, se produjo a través de dos coordenadas: la adhesión a doña Beatriz y a Juan I y la fidelidad a los papas de Avignon. El aparato de fuentes para su conocimiento, estudiado por José Marques, procede de la Chancelaria de Don Joao I y de las Súplicas a Clemente VII y a Benedicto XIII. En el primer corpus encontraríamos el nombre de los clérigos procastellanos a quienes fueron confiscados sus bienes o fue perdonado su desser-

28 Istáas da Rosa PEREIRA, $A$ vida do clero..., p. 134. El arzobispo ordena que «... por estas cousas melhor saberdes e as poder ensinar, mandamos que as façedes screver em hum caderno pera ele as saberdes e poderdes ensinar mais compridamente».

29 José MARQUES, «Clérigos portugueses exiliados e beneficiados em Castela Nova e na Andaluzia nos finais do século XIV», en Relaçoes entre Portugal e Castela nos finais da ldade Média, Lisboa, Fundaçao Calouste Gulbenkian/Junta Nacional de Investigaçao Científica e Tecnológica, 1994 (Textos Universitarios de Ciências Sociais e Humanas), pp. 283-303.

$30 \mathrm{El} 4$ de noviembre de 1386 Urbano VI absolvió a Joao da Veiga, a Silvestre Esteves, a Estevao Afonso y a sus colaboradores de la muerte del obispo don Martinho y del prior de Guimaraes Gonçalo Vas, quienes habian querido entregar la ciudad de Lisboa a los cismaticos, es decir, a los castellanos (AN/TT, NA, $n^{\circ} 42$, Traduçoens de Breves e Bulas, fol. I). 
viço al rey ${ }^{31}$ En el segundo aparecerían notificados los beneficios de clérigos portugueses exiliados en Castilla ${ }^{32}$. La secuencia temporal sería la siguiente. Del 1 de marzo al 12 de agosto de 1385 , coincidiendo con la invasión castellana, se produciría la mayor parte de las concesiones de beneficios portugueses a clérigos castellanos. A partir del 31 de enero de 1387 la tendencia sería la contraria. Por lo que respecta al primer caso, no se trata de beneficios reales, ya que el reino se encontraba en estado de guerra; la mayoría de los clérigos, 16 en total, proceden de Ávila, Badajoz, Ciudad Rodrigo, Córdoba, Sevilla y Valladolid y se instalan en Braga, Coimbra, Évora y Lisboa. Por lo que atañe a los segundos, destaca su número, muy alto, la ubicación de sus nuevos beneficios castellanos en las actuales Castilla-La Mancha (Cuenca, Toledo y Sigüenza), Extremadura (Badajoz y Plasencia), Andalucía (Sevilla, Córdoba y Cádiz) y Murcia (Cartagena) y la fuerte resistencia del clero castellano a su integración en sus cuadros; en su mayoría proceden de Braga ${ }^{33}$, Coimbra, Ciudad Rodrigo - vertiente portuguesa - Évora, Lisboa, Viseu, Guarda y Silves, existiendo cierta correspondencia entre Braga/Évora-Toledo, Évora/CoimbraPlasencia y Lisboa-Sevilla. Tanto en un caso como en otro, la presencia de intercesores a la hora de obtener beneficio muestra la existencia de un claro clientelismo social a finales del siglo XIV y principios del XV. A favor de los castellanos en Portugal encontramos a Juan I, al obispo de Coimbra y embajador de Juan I en Avignon Juan Cabeza de Vaca, al hijo del rey y también embajador en la curia aviñonesa Don Juan Manuel, al embajador en Avignon Juan Sánchez, al conde de Trastámara, al obispo de León y al maestre de Santiago García Fernández de Villa García. A favor de los portugueses en Castilla algunos nombres se repiten como los de Juan I o Juan Cabeza de Vaca, mientras aparecen otros nuevos como los del infante Don Dinis, hijo de Pedro I e Inés de Castro y rehén de los castellanos, el maestre de Alcántara Martinho Anes da Barbuda, la reina Doña Beatriz, Doña Teresa de Toledo, hermana del fallecido cardenal de Santa Sabina Don Guterre, la mujer del duque de Valencia Joao de Portugal, el cardenal de Venecia, el Estudio General de Avignon o la noble viuda sevillana María Coronel.

\footnotetext{
31 La confiscación de bienes afectó a todos los estamentos. El 10 de septiembre de 1384 el Maestre de Avis expropia a Violante Afonso por colaborar con Castilla y traspasa sus bienes a Vasco Martins de Melo (AN/TT, CE, caixa 32, $n^{\circ} 50$ ).

32 Antonio Domingues de Sousa COSTA, Monumenta Portugaliae Vaticana, vol. I, Roma/Porto, 1986 y vols. II y IV, Braga/Porto, Editorial Franciscana, 1970.

33 José MARQUES, «Braga na crise de 1383-1385», en Relaçoes entre Portugal e Castela nos fnais da Idade Media..., p. 254. En un rollo de súplicas del 25 de septiembre de 1388 Juan I solicita uлa canonjía en Toledo para Martim Afonso, deán de Braga, otra en Burgos para Gil Peres, arcediano de Couto y Braga, y una prebenda en Palencia para Gonçalo Esteves, canónigo bracarense y rector de Santa María de Cervres. Todos ellos habían huido de Braga por haberse adherido al partido de Juan I, declarándose más tarde clementistas para acceder más fácilmente a un beneficio en Castilla.
}

$I^{\text {er }}$ Congreso de Historia de la Iglesia Hispania Sacra 51 (1999) 
Para la iglesia portuguesa el trasvase supuso la desorganización de sus sedes, salvo las de Oporto, Lamego y Viseu y un cierto retraso en la reforma de la pastoral y de la formación cultural del clero. Sin embargo Joao I aprovechó la situación para poner en práctica su política eclesiástica - la citada imposición de su jurisdicción sobre ciertas ciudades episcopales- sin encontrar apenas obstáculos. Por su parte, en Castilla la influencia de los clérigos portugueses no fue significativa, en claro contraste con la pujanza de los linajes de origen portugués establecidos en los territorios de la corona castellana como los Pimentel, Pacheco o Silva ${ }^{34}$.

\section{LA SEDE DE COIMBRA EN EL TRÁNSITO ENTRE LOS SIGLOS XIV Y XV35.}

La historia de la ciudad durante estos años está capitalizada por la presencia de la Universidad desde 1354, tras su traslado desde Lisboa ${ }^{36}$. En 1377 regresará a la rivera del Tajo, para no volver de forma definitiva a Coimbra hasta el año 1537. En Lisboa el 25 de octubre de 1400 se creará la cátedra de Teología y desde 1431 se impartirán las siete artes liberales, medicina, teología, decretales y filosofía, bajo el patrocinio del Infante don Enrique ${ }^{37}$.

La vida sinodal en la dí́cesis no fue muy activa, ya que existe un vacío de sínodos casi absoluto entre 1163 y $1521^{38}$. Pese a todo, se conoce un sínodo de fecha incierta, probablemente de finales del siglo XIV -dato deducible del tipo de letra del manuscrito-, organizado quizá por Joao Esteves de Azambuja, obispo de Coimbra entre1398 y 1402, ya que como arzobispo de Lisboa

\footnotetext{
34 Emilio MrTRE FERNÁNDEZ, «La emigración de nobles portugueses a Castilla a finales del siglo XIV", Hispania, 104, XXVI (1966), pp. 513-525. La situación de los exiliados portugueses estuvo marcada por la derrota castellana en Aljubarrota. En un primer momento se reafirmó la posición de aquellos exiliados con anterioridad a la batalla; más tarde la guerra entre Castilla y Portugal dio un giro notable a su situación.

${ }^{35}$ Entre las historias diocesanas cabe destacar la História eclesiástica de Coimbra, 17, Biblioteca Nacional de Lisboa (BNL) código 148, microfilm F. 97.

${ }^{36} \mathrm{~A}$ la universidad acceden algunos monjes, como atestigua la bula Ecclesiaru Et Monasterium de 25 de marzo de 1375 en Avignon, por la que Gregorio XI permite al abad de Alcobaça mandar cuatro monjes a la Universidad de Coimbra a estudiar derecho canónico y civil (Pedro de AZEVEDo, «A colecçao do Visconde de Carreira»...).

${ }^{37}$ Miguel de OLIVEira, Historia eclesiástica de Portugal..., p. 168.

${ }^{38}$ Las primeras constituciones diocesanas datan de 1521. Las primeras constituciones sinodales impresas son las de Fray Joao Soares de Albergaria (1545-1572), obispo de Coimbra, conde de Arganil, confesor de Joao III y maestro del príncipe Don Joao y las de Don Afonso de Castel Branco (1585-1615), obispo de Coimbra, conde de Arganil y consejero de los reyes Felipe II y Felipe III. Constituçoes Synodaes do Bispado de Coimbra, Coimbra, 1548 y Constituçoes Synodaes do Bispado de Coimbra, Coimbra, 1591 y 1731. Resulta inevitable recordar aquí el trabajo de Isaías da Rosa PEREiRA, Sínodos medievais portugueses: séculos XIII-XV, Salamanca, 1978.
}

$\mathrm{I}^{\text {er }}$ Congreso de Historia de la Iglesia Hispania Sacra 51 (1999) 
promovió el ya citado de $1403^{39}$, aunque otros autores lo atribuyen a Juan Cabeza de Vaca (1377-1386) o a Martinho Afonso Pires de Charneca (13921397).

El sínodo establece que los priores han de guardar los traslados de los testamentos, para que pueda ser controlado su cumplimiento durante las visitas pastorales a las distintas iglesias. Priores, vicarios perpetuos, racioneros y frailes de iglesias, monasterios y conventos han de decir misa de día los domingos, salvo en caso de «doença», «per gram necessidade» o por licencia episcopal y bajo pena de perder las rentas del día, quedando al margen de tal disposición los canónigos y racioneros de la catedral ${ }^{40}$. Los priores de iglesias y colegiatas deberán celebrar además la misa de Navidad, Pascua, Pentecostés, San Juan Bautista, Todos los Santos y festividades de la Virgen, bajo pena de ser suspendidos del disfrute de las rentas de su beneficio durante un mes, quedando al margen otra vez los canónigos y racioneros catedralicios y aquellos liberados por enfermedad, necesidad imperiosa o licencia. Los priores de iglesias y colegiatas no deberán dar nada de las distribuciones de los Maitines y de los aniversarios y retendrán por seis días ración y prebenda a aquellos racioneros que no lleguen a cantar Maitines «ante que os primeiros tres psalmos de Sancta Maria sejam acabados» 0 al oficio en honor de la Virgen el día de su festividad «ante que o primeiro psalmo seja acabado ${ }^{41}$. Los seglares no deben recibir préstamos ni de las iglesias ni de los monasterios, a no ser que éstos sean abogados, procuradores, notarios o escribanos de dichas instituciones. Priores, vicarios perpetuos, racioneros, capellanes y clérigos deberán publicar durante las festividades religiosas la constitución sinodal por la que se prohibe enajenar bienes eclesiásticos sin licencia del obispo, bajo pena de excomunión. Por último, dichos eclesiásticos no podrán arrendar iglesias y beneficios a «cavaleiros, nem a donas, nem a molheres filhas dalgo, nem a homees poderosos», según «constituçom que he ordinhada de gram tempo» ${ }^{42}$.

En este tiempo, el deán Rui Lourenço refutó al cardenal y legado clemen. tista Pedro de Luna en la asamblea del clero de Santarém (19/5/1381), dando muestras de la existencia de un fuerte partido urbanista en el cabildo conimbricense, contrario al obispo Juan Cabeza de Vaca, clementista declarado ${ }^{43}$. También cabe destacar entre el clero catedralicio del momento al canónigo Gil

\footnotetext{
${ }^{39}$ Antonio de Brito CARDoso, A Diocese de Coimbra. Esboço Histórico, Coimbra, 1995, p. 33.

40 SYNODICON Hispanum. Portugal (dir. Antonio GarCía Y GarCía), vol. II, Madrid, BAC, 1982, p. 198.

41 lbid., p. 199

42 lbid., p. 199.

${ }^{43}$ Antonio de Brito CARDoso, A Diocese de Coimbra..., p. 18. 
Pires, quien acudió como representante del obispo al Concilio de Constanza $(1414-1418)^{44}$.

El Cisma de Occidente alteró la vida de la diócesis, ya que se sucedieron diversos obispos que no contaron con apoyos en el seno de la misma. Éste es el caso del citado Juan Cabeza de Vaca, quien fue sustituido en 1382 por teóricamente el obispo de Pesaro Fray Angelo de Bibbiena, , nominado sin efecto por Clemente VII. Juan Cabeza de Vaca terminó por refugiarse en Castilla en 1384 , acosado por los urbanistas y por los anticastellanos ${ }^{45}$.

La catedral contaba con 40 canongías, en vigor desde el episcopado de Martim Gonçalves hasta 1414, momento en el que se reducen a 30 por el descenso de las rentas, tras reclamación del cabildo a Roma a través del obispo Gil Alma (1408-1415) ${ }^{46}$. Desde 1361 se incorporan terciarios -cobran sólo un tercio de la prebenda- para suplir la falta de canónigos en el oficio divino de la catedral, dato que da cuenta del incumplimiento de la residencia por parte del clero catedralicio ${ }^{47}$.

El cisma y la guerra dificultan la configuración del episcopologio conimbricense. Su configuración por cuanto atañe a la segunda mitad del siglo XIV $\mathrm{y}$ primeros años del $\mathrm{XV}$ ha sido muy controvertida. A la que presentamos en este artículo, hay que añadir la de Francisco Leitao Ferreira -que será comentada más adelante-y la de Miguel Ribeiro de Vasconcelos ${ }^{48}$.

44 ID., Súmula da historia da Diocese de Coimbra, Coimbra, 1980. Es separata del Boletim da Diocese de Coimbra, I (1980).

45 Artur Roque de ALMEIDA, Para ler a história..., pp. 75-113.

${ }^{45}$ Antonio de Brito CARDOSO, A Diocese de Coimbra..., p. 38.

47 lbid., p. 39.

48 Miguel Ribeiro de VASCONCELOS, Catálogo ou relaçao nominal dos bispos de Coimbra desde a restauraçao do poder dos arabes em 1064 até ao presente, Coimbra, Universidade, 1859. El esquema de ambos listados sería el siguiente:

F.L. FERREIRA:

1. Pedro Gómez Barroso (1358-1364)

2. Vasco Fernández de Toledo (1364-1365)

3. Fernando $(1371-i$ ?

4. Pedro Tenorio (1371-1376)

5. Juan Cabeza de Vaca (1379-1385)

6. Martinho (1388-1391)

7. Fernando (1391-1392)

8. Martinho (1392-1397)

9. Joao (1398-1402)

10. Juan García Manrique (1402-1403)

M.R. VASCONCELOS:

1. Pedro Gómez Barroso (1358-1364)

2. Vasco Fernández de Toledo (1364-1371) 
La jurisdicción de la ciudad pasa a manos de la monarquía, como ocurre por estos mismos años con Oporto y Braga, pudiendo los oficiales reales cobrar impuestos a los criados y servidores del clero catedralicio ${ }^{49}$.

\section{OBISPOS CONIMBRICENSES DE ORIGEN CASTELLANO (1358*1407).}

\subsection{Pedro Gómez Barroso (25/8/1358-1364).}

Pedro Gomez Barroso de Albornoz, nacido en Toledo hacia 1321, fue canónigo de Palencia (1335) y de Toledo (1337), sede en la que accedió al arcedianato (1341) y al deanato. Su familia —era hijo de Femán Pérez Barroso, señor de Parla y Calabazas, y de Doña Mayor - contaba con ilustres antecedentes en la vida clerical. Su tío fue Pedro Gómez Barroso, obispo de Cartagena y también cardenal, nacido en Toledo a finales del siglo XIII y fallecido en el monasterio avignonés de España el 14 de julio de 1348.

El primer obispado de Gómez Barroso fue el de Sigüenza por nombramiento de Clemente VI (14/8/1348), desde donde fue trasladado a Coimbra (25/8/1358). Allí sucede al obispo Lourenço. Su marcha a Portugal responde a un exilio forzoso, al que se vio abocado tras ser encarcelado por Pedro I por su defensa de Blanca de Borbón ${ }^{50}$ y liberado más tarde por el cardenal Guido de

3. Pedro Tenorio (1371-1378)

4. Juan Cabeza de Vaca (1378-1384)

5. Martinho (1386-1395)

6. Martinho (1396-1398)

7. Joao Esteves d'Azambuja (1399-1402)

8. Juan García Manrique (1403-1407)

${ }^{49}$ En 1395 el rey establece una tasa sobre las caballerías y bestias de carga, de la que no están exentos los servidores de la Iglesia - incluidos los del obispo -, y de la Nobleza. Se trata de un gravamen fijo de 3 libras y 30 sueldos anuales, pagaderos el $1^{\circ}$ de abril. Su cuantía no varía se tengan uno o cuarenta caballos o mulas, lo que beneficia a los más pudientes ( $A N / T T, N A, n^{\circ} 287$, Tombo dos Foros Reais em Coimbra, fol. $\mathrm{X}$ r).

50 Pedro Álvares NogueIRA, Livro das vidas dos bispos da Sé de Coimbra, escritono século XVI pelo canónigo Pedro Álvares Nogueira (ed. Antonio GOMES DA ROCHA MADAHIL), Coimbra, Publicaçoes do Arquivo e Museu de Arte da Universidade de Coimbra, 1942, pp. 122-124. Al parecer fue el encargado de la vigilancia de la reina en sus traslados de Valladolid, Arévalo y Toledo. En esta última ciudad se produjo el levantamiento del Maestre de Santiago Don Fadrique, del conde Don Enrique, de Don Tello, del infante de Aragón Don Femando, de Don Juan Alfonso de Alburquerque y de Don Fernando de Castro. EJ rey cercó Toledo y terminó entrando por la puerta de San Martín: Doña Blanca es trasladada a Segovia, los revoltosos huyen a Talavera y Don Pedro es encarcelado por tomar partido por la desgraciada reina. Sus castillos y hacienda fueron embargados y se le trasladó a Aguilar de Campoo bajo la vigilancia de Gonzalo Gonzálvez de Lucio.

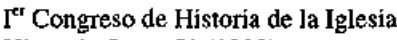
Hispania Sacra 51 (1999) 
Bolougne -mediador en la guerra entre Castilla y Aragón ${ }^{51}$ - En el vecino reino accedió también a la sede de Lisboa por traslado de Urbano V (23/7/1364). De vuelta a Castilla fue designado arzobispo de Sevilla (4/6/1369). Su carrera eclesiástica llegó a su cima con el nombramiento como Cardenal de Santa Práxedes por parte de Gregorio XI (30/5/1371). De su dilatada actividad intelectual y jurídica destaca el tratado Del consejo y consejeros de los Príncipes ${ }^{52}$. De su labor cardenalicia cabe destacar el apaciguamiento de los litigios entre los caballeros de San Juan de lengua francesa e italiana ${ }^{53}$. Murió en Avignon en 1374.

De su episcopado conimbricense conocemos escasos datos. Casi siempre actuó a través de sus vicarios generales, lo que denota escaso respeto por el deber de residencia La mayor parte de la documentación consultada nos remite a asuntos hacendísticos relacionados con el cabildo.

Durante su mandato el cabildo determinó celebrar dos aniversarios por año en memoria de Alvaro Pires a cambio de 20 libras, dos olivares y dos viñas $(1364)^{54}$.

El 6 de febrero de 1360 Fernao Gil, vicario general del obispo don Pedro, dictó sentencia en la demanda entre el cabildo, a través de su procurador y canónigo Vasco Martim, y Bartolomeu Peiriel, testamentario del maestrescuela don Gistardo. El albacea había recibido 500 libras de dinero portugués del citado don Gistardo para comprar unas casas para el cabildo, que a su vez sirvieran como renta para sufragar los aniversarios por el alma del maestrescuela. El testamentario había comprado las casas, pero no las había dado al cabildo. Fue juzgado que entregase las casas al cabildo, en pública avenencia, entregando a su vez al procurador del cabildo un instrumento público, realizado y certificado por el notario Joao Martins, con el que renunciaba a las casas. La posesión de las mismas pasaba al cabildo con la condición de que hiciese tantos aniversarios como fuese el rendimiento de sus arrendamientos ${ }^{55}$.

51 El envío de legados pontificios para solucionar los conflictos políticos peninsulares fue algo habitual a lo largo de la Edad Media. El 26 de febrero de 1370 Gregorio XI dicta la bula Fide Digna por la que manda al obispo de Cominges Bertrand y al obispo de Brescia Agapito a la Península Ibérica para arbitrar las disensiones entre Fernando I y Enrique II. El 6 de febrero del siguiente año faculta a sus nuncios para congraciar a los reyes de Aragón, Castilla, Navarra y Portugal con la bula Dudum Felicis. Ambas en Pedro de AzEvEDO, «A colecçao do Visconde de Carreira»...

52 José Manuel NIETo SORIA, Iglesia y génesis del estado modemo en Castilla (1369-1480), Madrid, Departamento de Historia Medieval/Editorial Complutense, 1993, p. 439.

53 Q. ALDEA, T. MARTín y J. Vives, Diccionario de Historia Eclesiástica de España, vol. II, Madrid, Instituto Enrique Florez/CSIC, 1972, p. 1026.

54 Pedro Álvares NoGUEIRA, Compendio da historia ecclesiastica da see de Coimbra, 17--, BNL, Reservados COD. 18, fol. 19. El mismo manuscrito relata la historia de la sede conimbricense entre 1358 y 1407 , fols. 40-44.

55 AN/TT,II Incorporaçao (II), Corporaçoes Religiosas (CR), Cabido da Sé de Coimbra (CSC), $\operatorname{maço~} 17, n^{\circ} 780$. 
Tres días más tarde Fernao Gil dictó otra sentencia sobre la tercia de los bienes dejados al cabildo por Martim Peres de Sousa, canónigo, para aniversarios. Maria Domingues, manceba y testamentaria de Martim Peres, se compromete a dar al cabildo 9 libras durante tres años a partir del día de San Martín ${ }^{56}$.

El 25 de marzo del mismo año el vicario general dictaminó que el cabildo tuviera cada año por la décima de la iglesia de Cadima un moyo de pan mediado (dos cuartos de trigo y dos cuartos de cebada) y no lo ofrecido hasta ahora por el prior de dicha iglesia (dos partes de pan mediado). El documento es refrendado por el sello pendiente de la cancillería del obispo ${ }^{57}$.

Del 11 de enero de 1361 data un traslado en pública forma a través del notario del rey en Coimbra Gonçalo Martins a requerimiento de Joao Palmeiro, deán y cabildo de la sede de Coimbra, y por la autoridad ordinaria de Afonso Peres, alguacil general de la ciudad, y del citado Fernao Gil, vicario general del obispo don Pedro ${ }^{58}$.

El 19 de abril de 1362 el rey Pedro I concedió al obispo don Pedro jurisdicción definitiva sobre las tierras de Belmonte por los servicios prestados por el prelado en Roma — «elle em corte de Roma me ffiz e faz muito serviçio»—59.

El 7 de junio de 1362 Fernao Gil dictó sentencia contra el prior de Sousellas para que dejase libre la mitad de un casal en dicha localidad ${ }^{60}$.

De 22 de enero de 1363 data una procuración por la que Senhorinha Esteves, moradora de la rua de Aconque en Santarém, obispado de Lisboa, y mujer de Gonçalo Fernandes, en otro tiempo almojarife del rey Afonso IV en dicha villa, concede plenos poderes a Alvaro Gonçalves, su hijo, a Lourenço Vicente, su sobrino, a Domingos Martins, vicario de Espinho, y a Gonçalo Domingues, escribano de la cancillería del obispo de Coimbra, para las demandas que tiene contra el cabildo de Coimbra, contra Pero Martins y Estevao de Soveral, moradores de esta ciudad, contra los moradores de Eiras Pedrinhas y contra todos los otros caseros de dicho cabildo que tienen y poseen los bienes que fueron del obispo Gómez Barroso y de Henrique Esteves, canónigo, así como la orden para hacer avenencia con el dicho cabildo y así renunciar en su nombre a todo derecho sobre los dichos bienes ${ }^{61}$. Cinco días más tarde se firmó la

\footnotetext{
56 AN/TT, $H, C R, C S C, \operatorname{maço~} 6, n^{\circ} 346$.

57 AN/TT, II, CR, CSC, maço $5, n^{\circ} 234$.

58 AN/TT, $I, C R, C S C$, maço $5, n^{\circ} 278$.

59 AN/TT,II, CR, CSC, maço 39, $n^{\circ} 1649$, fol, 3 . El texto se encuentra recogido en un cuadernillo de 15 folios que versa sobre los lugares sobre los que el obispo conimbricense tenía jurisdicción y colecta, redactado por orden de la cancillería de Afonso $\mathrm{V}$ el 20 de diciembre de 1492.

${ }^{60}$ AN/TT, I Incorporaçao (I), CR, Santa Cruz de Coimbra, Livro II, Livro de Sentenças sobre Dizimas, séculos XIV a XVI, fols. 55r-56.

61 AN/TT, $I, C R, C S C$, maço 6, $n^{\circ} 310$.

Ir Congreso de Historia de la Iglesia

Hispania Sacra 51 (1999)
} 
avenencia y acuerdo entre el cabildo de Coimbra y Senhorinha Esteves. El cabildo se compromete a pagar 110 libras de dineros portugueses a cambio de la renuncia de la otra parte a sus derechos. Se cita en el documento a Fernao Gil, vicario del obispo don Pedro ${ }^{62}$.

Pot último el 7 de diciembre de 1369, cuando don Pedro era ya obispo de Lisboa, Fernao Gil, titulándose aún canónigo y vicario general del obispo don Pedro, dicta sentencia por demanda entre el deán y el cabildo sentencia de la que daremos cuenta más adelante ${ }^{63}$. La pervivencia de la autoridad de Gómez Barroso en la diócesis demuestra el carácter interino del mandato de Vasco Fernández, que de inmediato pasamos a comentar.

\subsection{Vasco Fernández de Toledo (23/7/1364-7/3/1371).}

Blas o Vasco Fernández fue deán de Toledo y obispo de Palencia (12/9/1343). Hijo de Fernando Gómez, hermano del privado, camarero y repostero mayor de Pedro I Gutierre Fernández de Toledo y sobrino del arzobispo de Toledo Gutierre Gómez (+5/9/1319), alcanzó el grado de arzobispo de Toledo por influencia de su hermano y del rey. Su elección fue confirmada por Inocencio VI el 17 de junio de 1353. Inició una política reformadora en la archidiócesis, de la que son testigos el sínodo de Alcalá de Henares de 1354 y el concilio provincial de Toledo de 1355. También colaboró vivamente con los legados pontificios, el obispo de Senez y el cardenal Guillermo de Jugie. Durante su mandato el cabildo toledano permutó el señorío de Illescas. Al caer en desgracia tuvo que marchar al exilio a Portugal ${ }^{64}$. Tras un período indeterminado de sede vacante fue nombrado obispo o administrador apostólico de la diócesis de Coimbra ${ }^{65}$, ciudad en la que residía desde 1360 , en el convento de Sao Domingos ${ }^{66}$. Murió el 7 de marzo de 1371 en el citado convento ${ }^{67}$, aunque su cuerpo fue trasladado años más tarde a Toledo ${ }^{68}$.

62 AN/TT, H, CR, CSC, maço $6, n^{\circ} 310$.

63 AN/TT, H, CR, CSC, maço 15, $n^{\circ} 676$.

64 Pedro Álvares Nogueira, Livro das vidas dos bispos..., pp, 124-126. Tras la decapitación de su hermano, el canciller del selto de la poridad Mateo Fernández le notificó su destierro a través del todavía alcalde mayor de Toledo Pero López de Ayala. El arzobispo se encontraba rezando en su capilla y sólo tuvo tiempo para llevarse su hábito y su libro de oraciones. Se le embargaron sus propiedades y sus servidores - almojarifes, tesoreros y oficiales - recibieron tortura. En Portugal fure nombrado obispo conimbricense por Fernando I.

65 lbid.

66 Ibid.

67 Antonio de Brito CARdoso, Catalogo dos bispos de Coimbra, Coimbra, 1985, p. 7.

68 Q. AldEA, T. MARTín y J. ViVES, Diccionario..., vol. II, p. 922. Fue enterrado delante del altar de Santa María la Blanca. 
Por lo que respecta a su administración o episcopado conimbricense cabe repetir algunos de los aspectos ya comentados para el mandato de Gómez Barroso, aunque existen pruebas documentales evidentes de su residencia en la sede.

Conocemos una sentencia de su vicario, Joao Rodrigues, a favor de la abadesa y religiosas del Monasterio de Lorvao (5/5/1368) y una composición entre el propio don Vasco y el cabildo, de una parte, y don Domingos Coelho, prior de Rates, de la otra $(1370)^{69}$.

También se sabe que el domingo 20 de febrero de 1362 fue consagrado como obispo Fray Afonso de Noya en San Francisco de Coimbra, acto al que asistieron don Vasco, en calidad de arzobispo toledano, el obispo de Viseo y el obispo Fray Gil ${ }^{70}$.

De 2 de diciembre de 1364 data una sentencia de acuerdo entre partes, dictada por el citado Joao Rodrigues, prior de Teixoso en el obispado de Guarda y vicario general del obispo don Vasco, en el pleito entre el cabildo de Coimbra, teniendo como procurador a Jóao Martins, y Homem Martins, prior de la iglesia de Sao Cristovao, teniendo como procurador a Nicolao Peres, racionero de la dicha iglesia, por razón del cumplimiento de las cláusulas del testamento de Estevao Domingues. Fue acordado que la iglesia de Sao Cristovao daría al cabildo 8 libras por año por las heredades de Estevao Martins, para que el cabildo le hiciese dos aniversarios al año. El documento tiene sello de la cancillería del obispo de Coimbra ${ }^{71}$.

El 25 de febrero de 1365 don Vasco manda a los escribanos de la cancillería episcopal que escriban las causas del cabildo sin requerir a cambio sueldo o tasa alguno, medida que podemos considerar reformadora ${ }^{72}$.

El 1 de abril de 1365 otro de sus vicarios, el canónigo Joao Afonso, dicta sentencia en el pleito entre el cabildo y Maria Afonso, mujer de Afonso Peres, por razón de la quinta de Tremoa, término de Miranda. La quinta había sido de Domingo Peres y de su mujer Maria Martins, de la que Maria Afonso era hija adoptiva y única heredera. Se exige que Maria Afonso entregue la quinta que estaba en posesión de Clara Martins, segunda mujer de Domingos Peres, que la tenía arrendada al cabildo, y se determina que Maria Afonso tenga cada año

\footnotetext{
69 Francisco Leitao FERREIRA, Catalogo chronologico-crítico..., fols. 114-116.

70 LVRO da Noa do Mosteiro de Santa Cruz de Coimbra, AN/TT, 0396, Fondo José Manuel da Costa Basto CF 43, fol. 23r. El mismo anal portucalense cita la muerte del arzobispo, desterrado de Castilla por «sanha del rey» y retirado al Monasterio de Santa Cruz de Coimbra, y da una fecha a todas luces errónea: el lunes 7 de marzo de 1362. Vid. Ibid., fols. 23r-24.

11 AN/TT, II, CR, CSC, maço 24, $n^{\circ} I 002$.

${ }^{72}$ AN/TT, $I, C R, C S C$, maço $12, n^{\circ} 586$.

$I^{\text {er }}$ Congreso de Historia de ]a Iglesia Hispania Sacra 51 (1999)
} 
del silo del cabildo dos cuartos de trigo y un cuarto de mijo, según la medida antigua de Coimbra ${ }^{73}$.

De 16 de mayo de 1366 data un traslado en pública forma de cartas de venta $(3 / 3 / 1280)$, donación $(29 / 5 / 1289)$ y sentencia (17/4/1289) a tequerimiento de Domingo Martins, vicario de Espinho, procurador y proveedor de las tierras del cabildo que fueron de Santa Betaça, y por autoridad ordinaria del citado Joao Rodrigues, medio canónigo y vicario general del obispo don Vasco. Actúan como testigos Joao Martins, Joao Domingues, Alvaro Bentes y Joao Domingues de Acunha, notario de la cancillería episcopal ${ }^{74}$.

De 12 de junio del mismo año conocemos otro traslado en pública forma de carta de aforamiento de 5 de noviembre de 1288 a requerimiento del procurador general del cabildo de Coimbra, Joao Afonso, y por autoridad ordinaria del vicario general Joao Rodrigues ${ }^{75}$.

El 12 de abril de 1368 Afonso Martins Alvernaz, juez del rey en la ciudad de Coimbra, ordena a los agentes judiciales de Vacarica, Aquim, Vilanova de Monçarras, Casal de Comba y Vilanova de Outil, términos de Coimbra, que dejen los pleitos civiles a los jueces del obispo don Vasco o del cabildo de Coimbra. Dicha orden está incluida en un traslado de 10 de junio de 1368 a través del notario Gonçalo Martins ${ }^{76}$.

El 30 de agosto del mismo año Joao Rodrigues dicta sentencia sobre un tahonero que vivía en la parroquia de Sao Joao y trabajaba en la de Santiago para que pagase la mitad del diezmo en cada parroquia ${ }^{77}$.

Como hemos anticipado el 7 de diciembre de 1369 aparece un cruce de competencias con el equipo del otrora obispo Gómez Barroso. Así se produce una sentencia definitiva de acuerdo entre partes dictada por Fernao Gil, canónigo de Coimbra y vicario general del obispo don Pedro, en la demanda interpuesta entre el deán y el cabildo de Coimbra de una parte, teniendo como procurador y acusador al maestrescuela Guillermo, y Joao Rodrigues, escudero y vecino de Lisboa, en calidad de heredero y testamentario de su mujer Beatris Johanes, que fue en otro tiempo mujer y testamentaria de Pero Henriques, en otro tiempo canónigo de Coimbra, y Fernao Nunes, testamentario de Pais Daniel, ambos defensores de la otra parte, por causa de una media quinta cerca de Vilanova de Anços con todas sus pertenencias y de unas casas en la Rua Nova de Lisboa, las cuales el dicho cabildo arrendó en vida al dicho Pais Daniel y a

\footnotetext{
${ }_{73}$ AN/TT, $H, C R, C S C$, maşo 36, $n^{\circ} 1526$.

${ }^{74}$ AN/TT, II, CR, CSC, maşo 10, $n^{\circ} 500$.

${ }^{75}$ AN/TT, II, CR, CSC, maço 4, $n^{\circ} 159$.

${ }^{76}$ AN/TT, II, CR, CSC, maço IS, $n^{\circ} 699$.

${ }^{7}$ AN/TT, I, CR, Santa Cruz de Coimbra, Livro 11, fols. 56-57r.
} 
Beatris Johanes con renta de 60 libras por año, más 36 libras para que fueran oficiados aniversarios por el alma de Pero Graez, a quien pertenecían las dichas casas y media quinta. Como ambos enfiteutas no habían pagado las libras para la celebración de aniversarios y debían ya por misas 450 libras, sus testamentarios se ven forzados componer un acuerdo amigable con el cabildo, al que deben dar tres casas que están en el término de Sintra con todas sus pertenencias y una quinta cerca de Alcochete, propiedad de Pais Daniel y de Beatris Johanes, más la citada media quinta de Vilanova de Anços. Los defensores piden a cambio que el resto de los bienes quedase libre una vez dictada la sentencia definitiva de acuerdo entre partes. El texto se incluye en un traslado de 29 de agosto de 1443 a través del notario Lope Gil ${ }^{78}$.

El 29 de marzo de 1370 Joao Rodrigues dicta sentencia en la demanda entre el deán y el cabildo y Vasco Martins da Agua, morador de Coimbra, por razón de la quinta de Cabra en Penela que fue de Afonso Peres y de otra quinta de Cabra que fue de Nuno Fernándes, escudero, y que quedó para aniversarios de Mestre Martinho, quintas que Vasco Martins entregó al cabildo con todos sus derechos y pertenencias, reclamando a su vez tener derecho a sus frutos y rentas anteriores ${ }^{79}$.

Por último conocemos un traslado en pública forma de 26 de marzo de 1371 de instrumento de traslado de 1 de marzo de 1339 a través del notario Estevao Peres a requerimiento de Joao Afonso, medio canónigo de Coimbra, y por autoridad ordinaria del obispo don Vasco ${ }^{80}$.

Como hemos podido observar en la documentación capitular se considera a don Vasco obispo consagrado de Coimbra. Sin embargo las interferencias de los representantes de Gómez Barroso dan pistas en torno a una situación especial, aunque no hay que descartar errores en las fechas de los traslados.

\subsection{Pedro Tenorio $(19 / 5 / 1371-1376)^{81}$.}

Nacido en Tavira, en el Algarbe portugués, según algunos autores ${ }^{82}$, hoy en día se le considera natural de Talavera ${ }^{83}$ o Toledo ${ }^{84}$. Su linaje oriundo de Gali-

\footnotetext{
${ }^{78} A N / T T, I L, C R, C S C$, maço $15, n^{\circ} 676$.

79 AN7TT, $H, C R, C S C$, maço 27, $n^{\circ} 1109$.

${ }^{80}$ AN7TT, $I, C R, C S C$, maço $5, n^{\circ} 280$.

81 Para más información sobre el personaje y su relación con Portugal puede consultarse mi comunicación «Don Pedro Tenorio (ca. 1328-1399). Aproximación a la vinculación eclesiástica, familiar y política de un arzobispo toledano al reino de Portugal», IV Jornadas Luso-Espanholas de História Medieval (Porto, 27-29/11/1997) (actas en prensa).

82 Francisco Leitao FerReIRA, Catálogo chronológico-crítico..., 117-119. El autor cita a Pedro Álvares NOGUEIRA.
}

$I^{\text {er }}$ Congreso de Historia de la Iglesia Hispania Sacra 51 (1999) 
cia o Portugal, siempre estuvo muy ligado a los asuntos portugueses ${ }^{85}$. Estudió en Toulouse y Bolonia y se refugió en Portugal tras la batalla de Nájera (1367), todo ello antes de acceder al obispado de Coimbra (19/5/1371) ${ }^{86}$. Durante su mandato participó en la embajada portuguesa con motivo del matrimonio de Beatriz de Portugal. Al surgir una serie de problemas con el cabildo, fue desterrado a Ruan y apartado del gobierno de la dibcesis ${ }^{87}$. Gregorio XI le traslada a Toledo en 1377. Su promoción al arzobispado pone fin a las luchas en el cabildo por la sucesión de Gómez Manrique y a las pretensiones de su sobrino, Juan García Manrique, del que hablaremos más adelante. A lo largo de la campaña de Juan I en Portugal, fue el encargado de mantener y vigilar al infante Don Joao. Así, en 1383, en calidad de contador mayor del reino y regente, entrega 3.000 maravedís al infante y su soldada a los tres hombres encargados de su vigilancia en Almonacid. En 1384 le compra una cama con dos

83 Ibid. Según Tomás TAMaYo, sus padres serían Diego Alfonso Tenorio y Juana Duc, talaverana de pro. Para otros sería hijo de Martín Fernández Portocarrero y María Tenorio, hija de Alfonso Jofre Tenorio, almirante de Castilla, guarda mayor y consejero de Alfonso XI. Para Luis de SALAZAR Y CASTRO Don Pedro sería hermano de Urraca Tenorio, casada con Ayres Gomes da Silva, alcaide mayor de Guimaraes, señor de Ourem y ayo de Fernando I. Ambos serían hijos del citado Alfonso Jofré Tenorio y de Elvira Álvarez.

84 lbid. Según Eugenio NARBona.

85 Jofre Tenorio, Almirante de Castilla $(+1340)$ derrotó en 1336 a la armada portuguesa del almirante mayor Manuel Pessagno, quien cayó prisionero junto a su hijo. Por su parte Men Rodríguez Tenorio huyo de Castilla por enemistad con Pedro I y se refugió en Portugal junto a otros castellanos "porque razoada se lhes dera ousado acoutamento nas fraldas de segurança» (Fernao LOPES). Sin embargo, los dos Pedros firmaron un acuerdo de extradición: Portugal entregaría a los castellanos a cambio de Pedro Coelho, Álvaro Gonçalves y Diogo Lopes Pacheco, asesinos de Inés de Castro refugiados en Castilla. Pacheco consiguió escapar, dejando para la posteridad la frase «que se fizera o troco de burros por burros», alusión a la candidez de unos y otros que confiaban en el respeto de su condición de exiliados. Los castellanos fueron trasladados a Sevilla y allí ajusticiados

B6 Pedro Álvares NogUeIRA, Livro das vidas dos bispos..., pp. 127-128. El episodio más conocido es el de sus pleitos con el cabildo por obligar a los canónigos a pagar tasas de cancillería por monitorios o avisos, por el impago de 450 libras al cabildo para la expedición de mensajeros la rey o por la excomunión de algunos canónigos por usurpar los diezmos de Sao Giao da Figeira entre otras cuestiones que veremos con más detalle más adelante. Su elección y gobierno coincide con la guerra entre Fernando I y Enrique II. Los últimos focos del petrismo - Zamora, Carmona, Ciudad Rodrigo, Alcántara, Valencia de Alcántara, Tuy, Coruña, Salvatierra, Allariz, Orense, Santiago, Lugo, Bayona, Milmanda, Araujo y Ribadeo - habían pedido protección y amparo al rey de Portugal y algunos castellanos habían buscado protección en Portugal, como el obispo de Ciudad Rodrigo don Alfonso, Fernando de Castro y su hermano Álvaro Ruiz de Castro o el maestre de Alcántara Pedro Girón y su hijo Martín Chamorro. La guerra estalló y Portugal consiguió la alianza de Muhammad de Granada y Pedro IV de Aragón. Las paces de Alcoutim (1371) y Santarem (1373) serían las encargadas de apaciguar el clima bélico peninsular.

${ }^{87}$ Provocado por los citados problemas con el reparto del diezmo con el cabildo. Para el conocimiento del diezmo en Portugaj $\mathrm{M}^{2}$ Isabel LóPEZ DIAS, «Consideraciones sobre el diezmo», en Actas das II Jomadas Luso-Espanholas de História Medieval, vol. II, Porto, 1988, pp. 663-676. 
almodraques, un colchón, un travesero, dos pares de sábanas, dos colchas, un estrado, dos alfombras y un almofre de sayal por valor de 3.113 maravedís y 6 dineros. Por último, un año más tarde, le hace entrega de una partida de plata, que incluye un tajador, dos escudillas, dos plateles y tres tazas por cuantía de 2.796 maravedís ${ }^{88}$. Tras una azarosa vida, implicada en todos los avatares políticos del momento, muere en $1399^{89}$.

Su actividad en Portugal no se limitó al agitado gobierno de la dícesis conimbricense. Así el 9 de octubre de 1378 participó en la provisión contra el arzobispo de Braga Lourenço Vicente, urbanista declarado, teniendo como adjuntos a Vasco Domingues, deán de Braga y defensor de la causa clementista en la sede, y a don Martinho, obispo de Silves ${ }^{90}$. Éste último pretendía ser elegido arzobispo, alegando su fidelidad a Clemente VII ${ }^{91}$. Don Lourenço, tras su suspensión inicial, fue reintegrado en el ejercicio de sus funciones como metropolitano bracarense ${ }^{92}$. Tenorio también influyo en el devenir del Cisma de Occidente en Portugal. En un principio, la neutralidad portuguesa se mantuvo a finales de 1379 gracias a la embajada del arzobispo toledano, enviado por Juan $\mathrm{I}^{93}$. Más tarde estalló una fuerte confrontación entre los jefes de los partidos clementista y urbanista, los citados don Martinho y don Lourenço. Finalmente Clemente VII envió las bulas Cum nos carissimus $(8 / 2 / 1384)$ y Copiosus in unum (29/3/1384) a Tenorio, reconociendo a Juan I como rey de Portugal y prestándose a la desviación de fondos de la cámara apostólica y de la cruzada hacia la financiación de la guerra contra el Maestre de Avis ${ }^{94}$.

En las cortes de Lisboa de 8 de agosto de 1371 se acordó que fuera necesario el refrendo de la asamblea para toda declaración de guerra y para la acuñación de moneda, y se exigió moderación y control del gasto por parte de la casa real de Femando I. En el acta se cita la presencia de todos los «bispos», entre ellos, es de suponer, Tenorio o al menos su procurador ${ }^{95}$.

El 20 de marzo de 1372 Fernao Gil, canónigo y vicario del obispo Pedro Tenorio, dicta sentencia contra un caserío de la Eireira para que pague todos

${ }^{88}$ Salvador Dias ARNAUT, A crise nacional dos fins do século XIV: a sucessao de Don Fermando, Coimbra, Faculdade de Letras/Institato de Estudios Históricos Dr. Antonio de Vasconcelos, 1960, p. 168. Datos recogidos de una carta de quitación de 20 de mayo de 1386, Biblioteca Nacional de Madrid (BNM), Mss. 13018, fols. 93-116.

${ }^{89}$ Antonio de Brito CARDOSO, Catálogo dos bispos...., pp. 7-8.

90 Francisco Leitao Ferrerra, Catálogo chronológico-crítico..., fols. 117-119.

91 Julio Cesar BAPTISTA, «Portugal e o Cisma do Occidente»..., p. 90.

92 Ibid., Apéndice I, pp. 180-182.

${ }_{93}$ Ibid., p. 82

${ }^{94}$ Ibid., p. 168.

${ }^{9.5}$ AN/TT, Cortes, maço $1, n^{\circ} 6$, fol. $1 \mathrm{r}$

$I^{\text {er }}$ Congreso de Historia de la Iglesia Hispania Sacra 51 (1999) 
los diezmos al Monasterio de Santa Cruz de Coimbra, según consta en el contrato de aforamiento ${ }^{96}$.

El citado Fernao Gil, «vigario geeral do honrrado padre e senhor Dom Pedro por mandado de Dios e da Santa Egreja de Roma bispo», dicta sentencia el 14 de julio del mismo año por la que manda que el prior de la iglesia de Santa Maria de Penacova Gil Eanes y sus sucesores den cada año al cabildo de Coimbra un moyo de vino, harina de lagar y un moyo de pan mediado, mitad trigo y mitad cebada, bajo pena de excomunión. A su vez, el prior descontará los cuatro moyos que ya debía al cabildo ${ }^{97}$.

Giral Pires, canónigo de Coimbra y vicario general del obispo don Pedro, dicta sentencia el 4 de agosto de 1373 por la que juzga que el cabildo de Coimbra debe tener las casas de Sobre Ripas que eran de Maria Domingues, manceba y testamentaria de Martim Peres de Sousa, así como las otras casas, viñas y heredades que fueron de Martim Peres, por razón del pleito y deudas que ella tenía con el cabildo, reservándole el usufructo de las casas y bienes mencionados que tras su muerte quedarán libres y pasarán integramente a manos del cabildo. Se incluye otra sentencia al respecto de 9 de febrero de $1360^{98}$.

Cuatro días más tarde, Rui Lourenço, racionero perpetuo de la Colegiata de Santa Justa de Coimbra y juez-comisario, dicta sentencia en el pleito y demanda entre el cabildo de Coimbra y los hijos de Lourenço Eanes, representados por su tutor y procurador Estevao Eanes, sobre unas casas, viñas y olivares que Francisco Vinagre, en otro tiempo canónigo de la catedral, dejara en su testamento al cabildo para que celebrara aniversarios. Condena a los hijos de Lourenço Eanes, en la persona de su tutor, a entregar al deán y al cabildo de Coimbra, en el plazo de ocho días y bajo pena de excomunión, dos casas en Coimbra -un piso alto en la Rua dos Tintureiros y una casa en la parroquia de Sao Salvador - y dos viñas con sus olivares en Algeara y Vale de Sao Romao. También les impone el pago de las costas y la entrega al cabildo de 42 libras sobre las rentas de los cuatro años anteriores, en el plazo de un año y bajo pena de excomunión. En apostilla de 10 de octubre de 1373 Rui Lourenço condena al tutor a pagar 20 libras y 18 sueldos de su patrimonio. El texto cita a los obispos don Pedro Gómez Barroso, don Vasco y don Pedro Tenorio y a dos vicarios de este último, Fernao Gil y Giral Peres ${ }^{99}$.

El 16 de septiembre de 1373 Giral Peres dicta sentencia en la demanda interpuesta entre el cabildo, teniendo como procurador y fiscal a Martim Do-

96 AN/TT, I, CR, Santa Cruz de Coimbra, Livro 11, fols. 167-169.

${ }^{97}$ AN/TT, $I, C R, C S C$, maço $10, n^{\circ} 463$.

${ }^{98}$ AN/TT, Il, CR, CSC, maço 7, $n^{\circ} 346$.

${ }^{99}$ AN/TT, II, CR, CSC, maço 1, $n^{\circ} 37$. 
mingues, de una parte y a Pero Domingues, labrador y morador de Coimbra y acusado, de la otra, por razón de la décima de pan que el acusado no quería pagar al cabildo por ser feligrés de Santa Justa, colegiata a la que pagaba regularmente el diezmo. Se determina que el encausado pague al cabildo de Coimbra una tercera parte de la décima de pan molido. Contra dicha sentencia apelaron el prior de la iglesia de Santa Justa de un lado y el cabildo del otro, teniendo este último como procurador a Joao Burgos, ante los vicarios de la Iglesia de Braga y Sede Vacante y más tarde ante Fray Nicolau, vicario del arzobispo de Braga don Lourenço, siendo dado de parte de la iglesia de Santa Justa libelo apelatorio en escrito contra el cabildo, al que contestó el cabildo afirmando que la Iglesia de Braga no podía ni debía ser juez del pleito porque el prior no había apelado conforme a derecho. Nicolau Martins, arcediano de Braga, dictó sentencia el 17 de mayo de 1374, condenando a la iglesia de Santa Justa por su actuación ilegal. El texto se encuentra incluido en un traslado de 4 de febrero de 1379 a través del notario Pero Diogo Gonçalves ${ }^{100}$.

De 30 de agosto de 1374 data la sentencia dictada por Giral Peres en el pleito entre Vicente Esteves, morador en Santa Combadao, rentero de la tercia pontifical que el cabildo de Coimbra tenía en la iglesia de Santa Maria de Tremoa da Terra de Montagua, de una parte y Esteves Martins, prior de la misma iglesia, de la otra. Por la primera parte, representada por el procurador del cabildo Joao Martins, fue alegado que el cabildo estaba en posesión de dicha tercia pontifical en concepto de pan, vino, ganados y todas las cosas que la dicha iglesia de Santa Maria había y debía haber, salvo limosnas y ofrendas, y que el prior no las quería entregar a Vicente Esteves. Se determina que el prior pague a Vicente Esteves la tercera parte que pertenece al cabildo. El documento incluye sello de cera pendiente del obispo de Coimbra ${ }^{101}$.

Entramos ahora de lleno en el pleito entablado entre don Pedro y el cabildo de Coimbra, pleito que no llegó a resolverse con la salida de Tenorio de la diócesis y que implica de alguna forma el intento por parte del prelado de introducir algunas reformas en la administración diocesana.

El 30 de diciembre de 1390 el cabildo de Coimbra apeló la sentencia dictada por el Padre Nicolau, vicario de la Iglesia Metropolitana de Braga, en la demanda entre el obispo don Pedro y el propio cabildo, por no querer pagar aquél los 15 marcos de plata que había dejado el obispo don Egas, con el consentimiento de Roma, para el deán y para el cabildo por rezar todos los días el Salve Regina y por ciertas tierras de Figueiredo y Couto de Sao Romao. El obispo se había negado también a pagar 450 libras que don Egas había dejado

${ }^{100}$ AN/TT, $I, C R, C S C$, mą̧o I7, $n^{\circ} 776$.

101 AN/TT, II, CR, CSC, maço I3, no 619 . 
para demandas y a entregar las tercias de las décimas pontificales de las iglesias de Sao Pedro, Sao Salvador, Sao Cristovao, Sao Bartolomeu y otras pertenecientes al arciprestazgo de Linhares. Estando en curso el pleito don Pedro fue trasladado a Toledo y don Martinho (1386-1391) fue elegido nuevo obispo conimbricense. Éste se negó también a entregar estas rentas al cabildo, alegando no ser sucesor directo de don Egas. La sentencia final fue favorable al obispo, por lo que el cabildo apeló ${ }^{102}$.

El 17 de julio de 1391 se llega a un acuerdo entre el obispo don Martinho y el cabildo antes de ser pronunciada en la Rota una sentencia sobre la demanda que entre ellos había por ciertas tercias, derechos de cancillería, 400 libras y 15 marcos de plata, expoliados al cabildo por el obispo don Pedro - «Spoliatos per Petrum Thenorio»- El documento tiene un sello pendiente y espacio para otro desaparecido ${ }^{103}$

De diciembre de 1392 conservamos tres documentos. El primero es una sentencia dictada por la Curia Pontificia sobre la demanda entre los obispos Pedro y Martinho y el deán y cabildo de Coimbra por la posesión de ciertas rentas y por el pago de tasas de cancillería al obispo. Se determina que el obispo pague al cabildo 450 libras de moneda antigua y que el cabildo quede exento del pago de las tasas. Ejerce como notatio apostólico Nicolau Bertaldi y el documento tiene sello pendiente con cordón y lacre rojo ${ }^{104}$. El segundo es otra sentencia dictada a favor del cabildo en la apelación a Roma sobre el pleito entre la institución y los obispos Pedro y Martinho. También tiene sello de cera pendiente ${ }^{105}$. El tercero y último es otra sentencia dictada por la Curia Pontificia en la demanda entre el obispo y el cabildo de Coimbra por los derechos de las tercias de las tercias de las décimas pontificales -restituidos al cabildo-de las iglesias de Sao Fagundo, Antanhol, Santo Mario, Santo Isidoro, Linhares, Cortiço de Baixo en Folgozinho, Juncaes, Figueiro, Vila Cortez, Vila Franca, Mesquitela, Avora, Vagos y Casais de Sever. Tiene cordón para sello pendiente que falta ${ }^{106}$.

El 27 de agosto de 1394 se llegaría a un acuerdo entre el obispo don Martinho Afonso Pires de Charneca (1392-1398) y el cabildo de Coimbra, tras la demanda que hubo entre ellos y que procedía de tiempos de los obispos don Pedro Tenorio y don Juan Cabeza de Vaca por razón de la posesión de 15 marcos de plata y de 450 libras de moneda antigua que los prelados pagaban todos los años al cabildo para sus gastos y por mor de las tercias de las tercias ponti-

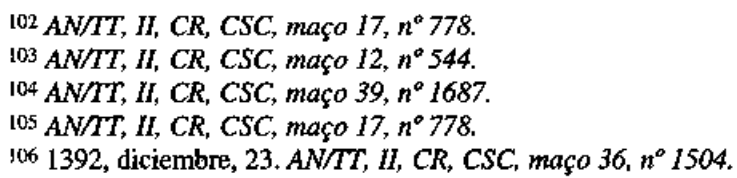

$\mathrm{I}^{\mathrm{er}}$ Congreso de Historia de ta Iglesia Hispania Sacra 51 (1999) 
ficales de las iglesias de Sao Pedro, Sao Salvador, Sao Cristovao, Sao Bartolomeu, etc... La sentencia de Roma había determinado que el dinero fuera para el cabildo y las tercias para el obispo. Sin embargo ambas partes acuerdan que las tercias de las iglesias de Miranda y Cernache sean para el cabildo en compensación por el dinero. El texto incluye procuración del obispo y del cabildo (31/8/1394), por la que se nombra al deán Rui Lourenço procurador ante el obispo de Oporto, ejecutor de la citada sentencia; procuración del obispo don Martinho (16/9/1394), por la que se nombra a Reimao Beltrao, prior de la iglesia de Sao Bartolomeu, procurador para otorgar la posesión de las tercias al cabildo; procuración del cabildo (5/10/1394), por la que nombra al chantre Pero Gonçalves y a los canónigos Vicente Anes, Paio Martins y Martim Fernandes procuradores ante Reimao Beltrao; y orden del obispo de Oporto, don Joao, (4/12/1394), por la que nombra a los medios canónigos Tomé Marques y Álvaro Bentes, a Domingues Martins, prior de Vacarica, y a Álvaro Vasques, prior de Freiximil, ejecutores para hecer cumplir en el plazo de 8 días el acuerdo de 27 de agosto de 1394. El acuerdo no se había cumplido todavía, según queja del cabildo ante el obispo don Pedro, nombrado ejecutor de la sentencia por Roma. El documento tiene dos sellos eclesiásticos de cera pendientes ${ }^{107}$.

\subsection{Juan Cabeza de Vaca (1377-1386).}

Don Juan Cabeza de Vaca inició su cursus honorum con el deanato de Toledo y el obispado de Coimbra (1377), sede en la que demostró ser un seguidor incondicional de Clemente VII. Colaborador de Juan I, actuó como embajador del monarca en la corte avignonesa en 1385. Diez años más tarde repitió embajada por la cuestión del Cisma. Su carrera eclesiástica continuó con su promoción a los obispados de Cuenca (1399-1406) y Burgos (1407-1413) ${ }^{108}$. Murió el 7 de enero de 1413.

Para algunos autores su episcopado en Coimbra se limita a los años 1377 y $1378^{109}$. Castellano, reside poco en la diócesis por las guerras entre Portugal y Castilla. Desde un principio tomó partido por Juan I. En 1383, a la muerte de Fernando I, se encuentra con la infanta doña Beatriz en Castilla. En 1385 se halla en Portugal junto al rey castellano, participando en el cerco de Cerolico da Beira, ya que su firma se encuentra en el testamento del rey de 21 de julio

${ }^{107}$ AN/TT, $I, C R, C S C$, maço $17, n^{\circ} 768$. Existe un traslado de 31 de octubre de 1468 a través del notario Rui Gonçalves en un cuaderno de papel de 12 hojas (AN/TT, $I, C R, C S C$, maço $17, n^{\circ} 769$ ).

108 José Manuel NIETO SORIA, Iglesia y génesis del estado modemo..., p. 428.

${ }^{10 \%}$ Fortunato de ALMEIDA, História da Igreja em Portugal, vol. I (dir. Damao PERES), Porto, Portucalense Editora, 1967, p. 502.

$I^{\text {er }}$ Congreso de Historia de la Iglesia Hispania Sacra 51 (1999) 
de 1385 en el real de dicha localidad. Como hemos anticipado, este traspaso de prelados a uno y otro lado de la frontera durante la guerra no es algo nuevo: don Rodrigo, obispo de Ciudad Rodrigo, se pasó a las filas de Joao de Avis y así lo encontramos entre los participantes en las cortes de Coimbra de 6 de abril de 1385.

Durante su mandato tuvo lugar una composición entre el obispo y el cabildo, de una parte, y la abadesa y religiosas del Monasterio de Lorvao, de la otra, sobre las visitas a las iglesias de Botao, Sao Martinho d'Arvore Freguesía y otras, probablemente en consonancia con las instancias reformadoras de su antecesor. El catálogo del Chantre de Evora habla de un tal Jorge como su sucesor, aunque en realidad le siguió un período de sede vacante ${ }^{110}$. El clima enrarecido que vivió la diócesis durante su episcopado podemos verlo en la privación por parte de Bonifacio IX de una canongía a Martim Ruiz por ser clementista declarado. El suceso supuso la puesta en marcha de una embajada de Juan García Manrique a Portugal y de' otra del deán conimbricense Rui Lourenço a Castilla' ${ }^{111}$.

De 12 de octubre de 1380 , en la localidad de Cantanhede, data una «carta de courados e paços» - de Fernando I en la que da cuenta de las casas y palacios pertenecientes al obispo de Coimbra «don Joao Cabeça de Vaca» en las que no pueden hospedarse ni tomar cosas los oficiales reales ${ }^{112}$.

E1 9 de junio de 1381 el vicario general dicta sentencia contra el obispo don Juan con la que declara nula otra sentencia anterior que él mismo había dictado contra el prior y el vicario del Monasterio de Santa Cruz de Coimbra, excomulgando a ambos por haber usurpado la jurisdicción del obispo, una vez comprobada la exención de jurisdicción episcopal del prior y del vicario. Probablemente nos encontramos en un momento en el que la autoridad del obispo castellano está cada vez más en entredicho ${ }^{113}$.

El 19 de agosto don Juan ya no ejercía como obispo, ya que conocemos una sentencia de Martim Domingues, quien se titula canónigo y vicario general de la sede vacante de Coimbra, por la que el Monasterio de Santa Cruz de Coimbra es reconocido beneficiario legal de los diezmos del Campo de Bollao, a pesar de que la capilla de Sao Joao de la iglesia de Barcouso tuviera en principio derecho a la mitad de las décimas ${ }^{114}$.

\footnotetext{
${ }^{110}$ Francisco Leitao FERREIRA, Catálogo chronologico-crítico..., fols. 119-123.

1 II Pedro Álvares NogUEiRA, Livro das vidas dos bispos..., p. 140.

112 AN/TT, 0729/R, Chancelaria de Dom Fermando I, Livro 2, fol. 73.

${ }_{113}$ AN/TT, I, CR, Santa Cruz de Coimbra, Livro 11, fols. 101-104.

114 AN/TT, I, CR, Santa Cruz de Coimbra, Livro 11, fols. 99-101.
} 


\subsection{Martinho Afonso Pires de Charneca (1392-1397).}

Don Martinho, de origen castellano, fue también víctima de las persecuciones de Pedro I, por lo que se refugió en Portugal. Participó en la batalla de Aljubarrota del lado portugués y fue elegido obispo de Coimbra en 1392, según carta de confirmación de la provisión de la iglesia de Abial por la abadesa de Lorvao (4/8/1392) y carta de Joao I (26/7/1397, Évora). Más tarde fue trasladado, no conociéndose con precisión su siguiente destino: el obispado de Évora o el arzobispado de Braga. Murió el 25 de marzo de 1416 en Lisboa y fue enterrado en la iglesia de Sao Cristovao ${ }^{115}$.

Como obispo conimbricense puso fin a los pleitos de Tenorio. Entre otros acuerdos el cabildo consiguí sus 15 marcos de plata por entonar el Salve Regina y el responso de Santa Clara, a través de las tercias de Sao Salvador de Miranda y Santa María de Sarnache. El obispo obtuvo la quinta de Avenal y la tercia de Sao Romao y las tasas de cancillería fueron suprimidas para las cartas, órdenes y sentencias y mantenidas para sentencias declaratorias y ejecuciones de sentencia ${ }^{116}$.

Como metropolitano de Braga celebró un sínodo el 15 de noviembre de 1398. Con él trató de poner remedio a la ruina del arzobispado, provocada por el Cisma y las guerras con Castilla. En el texto se acuerda la concesión al arzobispado de la mitad de todos los frutos y rentas de un año de toda iglesia, monasterio o priorato que quedase vacante para un período de seis años. El texto presenta en primer lugar las deudas del arzobispado ${ }^{117}$. En segundo término presenta las causas de la crisis económica: el arzobispado estaba herido de muerte «per as guerras que forom e som em estes regnos co'os castellaos per os quaas era tomada e ocupada hua gram parte do arcebispado na comarca d'Aleem dos Montes, hu o dicto arcebispado avia ha moor parte das suas rendas» y además «os paaços da dicta eigreja...e as camaras e granjas do dicto arcebispado...eram destroydas e aviam mester grande adubia e nom se podiam reparar sem grandes despesas» ${ }^{18}$. Por último, al no ser suficiente el citado canon sobre los beneficios vacantes para cubrir gastos, se acuerda entregar también dos décimas partes de las rentas de toda iglesia, monasterio o beneficio el día de Pascua durante cuatro años. El 5 de abril de 1402 celebró otro

\footnotetext{
IIS lbid., fols. 124-126.

116 Pedro Álvares NOGUEIRA, Livro das vidas dos bispos..., p. 146.

117 SYNODICON Hispanum. Portugal..., vol. II, p. 60: «hua grande quantia d'ouro por os froytos do primeiro anno (pagadera a la curia romana)" y "per razon da sua provison era obligado ao papa e ao collegio dos cardeaas por os serviços comuuns e mehudos... outra gran soma, que todo passa de oyto mill dobras castellaas» $\mathrm{y}$ «outrossy que era obligado a moytas pessoas».$$
118 \text { Ibid., p. } 60
$$

$I^{\text {er }}$ Congreso de Historia de la Iglesia Hispania Sacra 51 (1999)
} 
sínodo, del que se conservan dos constituciones que establecían respectivamente la excomunión y la privación de sepultura eclesiástica para aquellos hidalgos que usurparan bienes de iglesias y monasterios y también para aquellos abades, priores y rectores que se dejaran usurpar voluntariamente. Según el texto los hidalgos demandaban comedorias o yantares (derechos de hospedaje) a monasterios e iglesias; si no los recibían, imponían a sus administradores, quienes se encargaban de controlar «o pam e o vinho e carnes, cevadas e palhas» de iglesias y monasterios bajo la amenaza de talar panes y viñas si los abades, priores o rectores se oponían a tal imposición $n^{119}$. Clemente VI, ante las protestas de los clérigos de Braga, promulgó una serie de bulas en las que imponía severas penas para los usurpadores de bienes eclesiásticos; éstas fueron publicadas por los arzobispos sin resultado aparente, ya que tras la muerte de don Lourenço Vicente los nobles volvieron a reclamar derechos de hospedaje y a imponer su administración sobre iglesias y monasterios bracarenses. El sínodo impone la amonestación sobre «condes, ricos homeens, infançoes, cavaleiros, scudeiros e outras quaeesquer pessoas de qualquer estado e condiçion», salvo el rey, la reina y sus hijos ${ }^{120}$. También amonesta a los abades, priores y rectores de iglesias que según algunos hidalgos eran los culpables de la situación ya que «vaao pousar e comer nos dictos moosteiros e egrejas...per (su) mandado» ${ }^{121}$.

\subsection{Juan García Manrique (2/6/1402-1407).}

Nacido en el seno del linaje de los Manrique, tronco de la Casa de Nájera, fue hijo de Garci Fernández Manrique, señor de Amusco, adelantado y merino mayor de Castilla, y de Urraca de Leyva, hija de Juan Martínez de Leyva, consejero y camarero mayor de Alfonso $\mathrm{XI}^{122}$. Juan García Manrique, rival político de Tenorio, fue maestrescuela de la catedral de Santiago (1361), canónigo toledano, arcediano de Talavera y Calatrava (1367) y obispo de Orense (1371 1375) y Siguenza (1375-1381), siempre amparado por su tío, don Gómez Manrique, arzobispo de Santiago y Toledo. Precisamente, a la muerte de éste, una parte del cabildo toledano le eligió arzobispo de Toledo, elección a la que tuvo que renunciar por orden de Gregorio $\mathrm{XI}^{123}$. Con Enrique $\mathrm{I}$, de quien fue testamentario, ocupó los cargos de Notario Mayor de los Privilegios Rodados (1367), Notario Mayor del Reino de León, Oidor de la Audiencia Real, Canci-

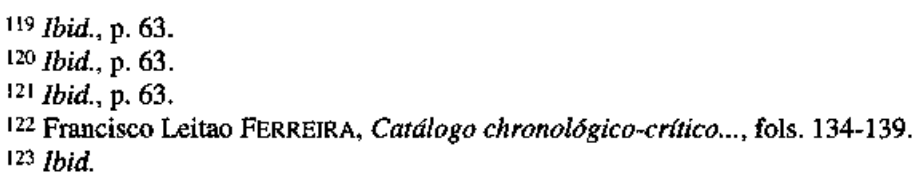


ller Mayor y Consejero. Con Juan I, de quien fue también albacea, continuó desempeñando el cargo de Canciller Mayor. Su carrera eclesiástica continuó con su promoción al obispado de Burgos (1381-1382) y al arzobispado de Santiago (1382-1398). Durante la minoridad de Enrique III actuó como regente y fue nombrado Oidor de la Audiencia Real, Canciller Mayor y presidente del Consejo Real. Pese a todo lo antedicho terminó siendo exiliado a Portugal por desavenencias con el nuevo monarca ${ }^{124}$. Tras la minoridad y las luchas por el poder se retir 6 de la Corte, se desnaturalizo, tomó partido por Joao I y se instaló en Portugal entre 1395 y 1398 . Esta rotunda decisión cabe atribuirla a su rivalidad con Tenorio, a la presión del Duque de Benavente ${ }^{125}$ y a su apoyo a la causa urbanista, aunque este último aspecto quizá fuera tenido en cuenta a posteriori por el prelado.

En el reino vecino fue administrador apostólico de la sede de Coimbra y de Sao Estevao de Valença do Minho ${ }^{126}$. Este último nombramiento responde a la siguiente razón: los obispos castellanos de Tuy nombraban vicariosadministradores de las tierras portuguesas de la diócesis; uno de los canónigos fieles a Roma tras el Cisma, don Toribio, se niega a reconocer la autoridad del obispo clementista, se traslada a Portugal y funda una nueva provincia eclesiástica en las citadas tierras, con sede en Valença do Minho; Juan García Manrique accede al cargo de administrador a la muerte de Toribio y crea en la localidad un auténtico obispado, nombrando canónigos, provisores y prebendados, disponiendo de beneficios y rentas, anexionando la colegiata del lugar, configurando los arcedianatos de Cervera y Labruja y regulando los oficios divinos ${ }^{\mathrm{i2}}$.

Juan García Mantique tenía experiencia previa en los asuntos portugueses. En 1365 había participado en los primeros contactos entre Enrique de Trastámara y Fernando I. También había colaborado en los acuerdos para la boda de Juan I con Beatriz de Portugal, el 17 de mayo de $1383^{128}$, y había formado parte de una embajada a Braga junto a Pedro de Luna, Enrique Manuel de Villena, conde de Seia, y el conde de Andeiro; de igual forma se conoce su

\footnotetext{
124 José Manuel NIETo SORIA, Iglesia y génesis del estado moderno..., p. 438.

125 Pedro Álvares NOGUEIRA, Livro das vidas dos bispos..., pp. 146-149. El duque y el arzobispo consiguieron juntar 1.200 lanzas y 2.000 peones para presionar al rey sin conseguirlo.

126 Francisco Leitao FERREIRA, Catálogo chronologico-crítico..., fols. 134-139.

${ }^{127}$ Fortunato de ALMEIDA, Historia da Igreja em Portugal..., vol. I, pp. 285-286.

128 Pedro Álvares NogueIRA, Livro das vidas dos bispos..., pp. 132-135 y 143-145. El autor destaca otros episodios anteriores: sa presencia en la confirmación de la paz de Alcoutim junto a Juan González de Bacón; su regreso a Portugal para conocer los contactos entre Fernando I y el Duque de Lancaster; su actuación en los pactos matrimoniales entre Doña Beatriz y el futuro Enrique III, una vez desechada la unión con don Fadrique y antes de ser procurador en la citada boda entre la infanta y Juan I.
}

$I^{\text {er }}$ Congreso de Historia de la Iglesia Hispania Sacra 51 (1999) 
presencia en el tratado de Salvaterra de Magos, al ser el encargado de recibir los juramentos de los concejos de las cortes de agosto de 1383 en Santarém en nombre del rey de Castilla ${ }^{129}$. Su experiencia portuguesa fue utilizada también por Clemente VII en el pleito por la elección de Álvaro Gonçalves Camelo como prior del Hospital, quien sustituiría a Pedro Álvares Perereira, cuyo linaje se había pasado en bloque a las filas urbanistas ${ }^{130}$.

En 1398 se le priva oficialmente del arzobispado compostelano. Sin embargo el 23 de enero de 1400 asiste a la consagración del altar mayor de Nosa Senhora de Oliveira, colegiata de Guimaraes, en calidad de arzobispo compostelano. Se tienen noticias de su labor en Coimbra en 1403, así como de algunas sentencias de su vicario Payo Martins, canónigo conimbricense, del 2 de enero de 1404. El día 20 se autotitula todavía arzobispo de Santiago y administrador apostólico de Coimbra y Tuy. Durante su administración conimbricense fallece el deán Rui Lourenço en Medina del Campo, durante las paces entre Portugal y Castilla, legando su biblioteca y un cáliz de oro a la sede portuguesa $^{131}$. Tras su alejamiento de la sede, se inicia un período de vacancia ${ }^{132}$. Algunos autores consideran que fue trasladado desde Coimbra a Braga $(1407)^{133}$, aunque dicho dato no puede ser contrastado con fiabilidad ${ }^{134}$. Al parecer murió en el convento de Sao Domingos en Coimbra, dejando su manto brocado y 30.000 libras para la talla de un coro; el cabildo de Coimbra en agradecimiento ordena que todos los días, acabada la prima, se dijese un responso delante del altar de Nuestra Señora ${ }^{135}$.

Como arzobispo compostelano había desarrollado cierta actividad reformadora. Así, fue el responsable de la constitución definitiva de la provincia compostelana - vigente hasta el concordato de 1451 - y de la fundación de aniversarios en la catedral y en la iglesia franciscana de Santa María a Nova.

También celebró un sínodo en Santiago de Compostela el 23 de julio de 1390 con el que pretendió regular las visitas pastorales. Éstas se deben realizar «cada anno» por parte del «deam et arçidiagos da nosa iglesia»; éstos deben

\footnotetext{
129 José MARQUES, «Braga na crise de 1383-1385", p. 244.

130 Julio Cesar BAPTISTA, «Portugal e o Cisma do Occidente»..., Apéndices XII-XIV, pp. 196203. En 1383, tras el cambio de provisión, el arzobispo compostelano fue el encargado de llevarla a efecto y de juzgar al antiguo prior, nombrado tres años atrás por el propio pontífice.

131 Pedro Âlvares NOGUEIRA, Livro das vidas dos bispos..., p. 149.

132 Francisco Leitao FERREIRA, Catálogo chronolbyico-crítico..., fols. 134-139.

133 Antonio de Brito CARDOSO, Catalogo dos bispos..., p. 8.

${ }^{134}$ Fortunato de ALMEIDA, História da Igreja em Portugal..., vol. I, pp. 499 y 502. En ésta ya clásica obra se da como segura la sucesión de Juan García Manrique al frente de la archidiócesis bracarense a la muerte de Don Lourenço (1397-1398), mientras se pone en dıda su titularidad como obispo o administrador de Coimbra.
}

135 Pedro Álvares NoGUEIRA, Livro das vidas dos bispos..., p. 149. 
visitar una iglesia al día, para obtener una procuración diaria; en el caso de que la visita a varias iglesias pequeñas equivalga a una sola procuración - procuraçom o collecta -, los visitadores pueden realizar su labor en un mismo día; la visita «non tan solamente enforma et ensina asy clerigos commo leigos, mais ainda correge os seus custumes et os seus autos et os seus excesos et maldades, castiga conmunalmente et a todos tira et respea de fazer mal» ${ }^{136}$. El texto prevé la suspensión de «ofiçio et benefiçio» para todo aquel que contraviniera las reglas de la visita pastoral ${ }^{137}$.

Por lo que respecta a la documentación emanada durante su periplo portugués cabe destacar el traslado en pública forma de 2 de julio de 1403 a través de Afonso Anes, notario del rey, de la carta de aforamiento de 20 de marzo de 1395 de un tercio de casal en el Vale de Ladroes por el cabildo a Afonso Pires y a su mujer Catarina Anes y realizado por autoridad ordinaria del vicario general de el «onrrado e nobre e padre e senhor dom Joham Mamriques, arçebispo de santiago e menestrador e regedor do bispado da dicta cidade de Coimbra ${ }^{138}$.

De 12 de septiembre de 1406 data una decisión sobre una pesquisa abierta entre los hombres buenos y antiguos moradores de Banhos sobre una heredad que se encontraba cerca del estanque del cabildo de Coimbra, a través del Almojarife del Condestable de Vila Nova de Anço, Estevao Domingues, y de Pedro Eanes y Joao Eanes, canónigos y procuradores del cabildo. Incluye una orden de la reina doña Beatriz de 27 de agosto de 1294 al almojarife para que deje libre el estanque de Anço. La decisión es de Afonso Lopes, prior de la iglesia de Sao Pedro y vicario general de Juan García Manrique, arzobispo de Santiago y administrador perpetuo de Tuy ${ }^{139}$.

Por último, una carta de confirmación, fechada el 1 de agosto de 1410 en Monte Moor o Novo, sobre la elección de Joao García como abad comendatario del Monasterio de Ganfey, a pesar de serlo ya del Monasterio de San Salvador da Torre, ambos pertenecientes al obispado de Tuy, quizá se refiera a nuestro prelado, ya que no morirá hasta el año $1416^{140}$.

Una vez analizados el contexto histórico y la actuación de los prelados, cabe concluir que la presencia de estos castellanos en Coimbra responde al carácter particular de la frontera luso-castellana, permeable -al menos por lo que atañe a un estamento intemacional como el eclesiástico - en un momento

\footnotetext{
136 SYNODICON Hispanum. Galicia (dir. Antonio GARCía Y GARCla), Vol. I, Madrid, BAC, 1981, p. 313.

${ }_{137}$ Ibid., p. 314.

${ }^{138}$ AN/TT, II, CR, CSC, maço $39, n^{\circ} 1639$.

${ }^{139}$ AN/TT, $l l, C R, C S C$, maço 4, $n^{\circ} 157$.

${ }^{140}$ AN/TT, J073/R. Chancelaria de Dom Joao I, Livro 3, fol, 69.
} 
de abierta hostilidad entre los reinos de Portugal y Castilla. El impulso reformador de dichos obispos queda aquí apuntado, siendo necesaria una profundización mayor al respecto en futuras investigaciones. 